\title{
Endoscopic Mucosal Healing as a Treatment Target in Ulcerative Colitis: Does It Have the Same Role in Asian Patients?
}

\author{
Suk-Kyun Yang, Sang Hyoung Park, and Byong Duk Ye \\ Department of Gastroenterology, Asan Medical Center, University of Ulsan College of Medicine, Seoul, Korea
}

Article Info

Received May 22, 2021

Revised May 31, 2021

Accepted June 14, 2021

Published online July 27, 2021

\section{Corresponding Author}

Suk-Kyun Yang

ORCID https://orcid.org/0000-0003-2772-2575

E-mail sky@amc.seoul.kr

\section{To the Editor:}

We read with great interest the article by Shin et al., ${ }^{1}$ which compared the outcomes of 131 ulcerative colitis (UC) patients in clinical remission according to the endoscopic mucosal healing status and the distribution pattern of mucosal inflammation. The authors reported that poor outcome-free survival was significantly higher in patients with endoscopic remission or only nonrectal inflammation than in those with rectal inflammation ( $\mathrm{p}=0.003$ ). Poor outcome-free survival in patients with only nonrectal inflammation was comparable to that in patients with endoscopic remission $(\mathrm{p}=0.647)$. In multivariable Cox regression analysis, rectal inflammation (hazard ratio, 5.76; $\mathrm{p}=0.027$ ) was the only predictor of poor outcome. Therefore, the authors suggested that treatment escalation may be selectively required in consideration of the distribution pattern of residual mucosal inflammation in UC patients in clinical remission.

Mucosal healing has emerged as a key prognostic factor in the management of UC. ${ }^{2}$ Previous studies have demonstrated that mucosal healing in UC is associated with prolonged clinical remission and lower risks of hospitalization, colectomy, and colorectal cancer. ${ }^{3-6}$ However, these studies evaluated only the grade of residual mucosal inflammation and did not consider the distribution pattern of residual mucosal inflammation. Moreover, most of these studies were conducted in Caucasian populations ${ }^{3-6}$ and only a few small-scale studies were conducted in Asian populations. ${ }^{7.8}$ The study by Shin et al. ${ }^{1}$ was the first to evaluate the distribution pattern of residual mucosal inflammation in UC patients in clinical remission and to compare disease outcomes according to the distribution patterns. In addition, this was the largest study to evaluate the prognostic role of mucosal healing in Asian patients with UC. Their results may provide a basis for minimizing unnecessary treatment escalation that potentially increases the risk of adverse effects.

However, before applying these results to clinical practice, we would like to address some concerns. First, although the definition of poor outcome in this study was step-up therapy, hospitalization, and colectomy, none of the 131 patients included in the study was hospitalized or underwent colectomy during the median follow-up of approximately 5 years. Consequently, outcome was assessed by the presence of step-up therapy alone. This is in contrast with previous Western studies, in which outcome was assessed by clinical relapse, hospitalization, and colectomy. ${ }^{3-6}$ Physicians may decide to adopt medication escalation earlier and more frequently in patients with residual rectal inflammation than in those with only nonrectal inflammation, even when the symptom status is similar between the two groups, because rectal inflammation is generally considered to evoke symptoms more frequently than nonrectal inflammation. In this regard, medication escalation may be a less objective outcome parameter than the others. Second, the finding of no hospitalization or colectomy during the median follow-up of approximately 5 years may indicate that the prognosis of Korean UC patients is better than that of Western 
UC patients. The genotypes and phenotypes of UC in Asia, where the incidence and prevalence rates of UC are still low but rapidly increasing, ${ }^{9-11}$ differ from those in Western countries. ${ }^{12}$ Notably, compared with the colectomy rate in Western UC patients, the rate in Asian UC patients is very low. ${ }^{13,14}$ Therefore, it is uncertain whether the result of this study showing the same risk of step-up therapy between patients with residual nonrectal inflammation and those with endoscopic remission can be generalized to Western UC patients who have a worse prognosis than Asian patients. Third, even if future studies confirm that nonrectal residual inflammation in UC patients in clinical remission is not associated with poor outcomes in terms of hospitalization and colectomy, this inflammation may still be associated with an increased risk of colorectal cancer in the long term. ${ }^{15}$

Therefore, further studies with longer follow-up durations and larger sample sizes are needed to assess the risks and benefits of treatment escalation for nonrectal residual inflammation in UC patients in clinical remission. We expect that the prospective observational cohort of Moderate-to-Severe Ulcerative Colitis in Korea (MOSAIK) will provide answers to this question. ${ }^{16}$ Although final conclusions still need to be made, the results of this study may still be useful for consulting patients and making treatment decisions. We can safely withhold treatment escalation in asymptomatic UC patients with residual nonrectal inflammation if they have a high risk of adverse events or are reluctant to undergo step-up therapy.

\section{CONFLICTS OF INTEREST}

No potential conflict of interest relevant to this article was reported.

\section{ORCID}

Suk-Kyun Yang https://orcid.org/0000-0003-2772-2575 Sang Hyoung Park https://orcid.org/0000-0002-5366-5749 Byong Duk Ye https://orcid.org/0000-0001-6647-6325

\section{REFERENCES}

1. Shin J, Kong SM, Kim TJ, et al. Clinical significance of residual nonrectal inflammation in ulcerative colitis patients in clinical remission. Gut Liver 2021;15:401-409.

2. Neurath MF, Travis SP. Mucosal healing in inflammatory bowel diseases: a systematic review. Gut 2012;61:1619-1635.

3. Reinink AR, Lee TC, Higgins PD. Endoscopic mucosal healing predicts favorable clinical outcomes in inflamma- tory bowel disease: a meta-analysis. Inflamm Bowel Dis 2016;22:1859-1869.

4. Frøslie KF, Jahnsen J, Moum BA, Vatn MH; IBSEN Group. Mucosal healing in inflammatory bowel disease: results from a Norwegian population-based cohort. Gastroenterology 2007;133:412-422.

5. Colombel JF, Rutgeerts P, Reinisch W, et al. Early mucosal healing with infliximab is associated with improved longterm clinical outcomes in ulcerative colitis. Gastroenterology 2011;141:1194-1201.

6. Ponte A, Pinho R, Fernandes S, et al. Impact of histological and endoscopic remissions on clinical recurrence and recurrence-free time in ulcerative colitis. Inflamm Bowel Dis 2017;23:2238-2244.

7. Saigusa K, Matsuoka K, Sugimoto S, et al. Ulcerative colitis endoscopic index of severity is associated with long-term prognosis in ulcerative colitis patients treated with infliximab. Dig Endosc 2016;28:665-670.

8. Yokoyama K, Kobayashi K, Mukae M, Sada M, Koizumi W. Clinical study of the relation between mucosal healing and long-term outcomes in ulcerative colitis. Gastroenterol Res Pract 2013;2013:192794.

9. Park SH, Kim YJ, Rhee KH, et al. A 30-year trend analysis in the epidemiology of inflammatory bowel disease in the Songpa-Kangdong district of Seoul, Korea in 1986-2015. J Crohns Colitis 2019;13:1410-1417.

10. Yen HH, Weng MT, Tung CC, et al. Epidemiological trend in inflammatory bowel disease in Taiwan from 2001 to 2015: a nationwide populationbased study. Intest Res 2019;17:54-62.

11. Ng SC, Leung WK, Shi HY, et al. Epidemiology of inflammatory bowel disease from 1981 to 2014: results from a territory-wide population-based registry in Hong Kong. Inflamm Bowel Dis 2016;22:1954-1960.

12. Thia KT, Loftus EV Jr, Sandborn WJ, Yang SK. An update on the epidemiology of inflammatory bowel disease in Asia. Am J Gastroenterol 2008;103:3167-3182.

13. Cha JM, Park SH, Rhee KH, et al. Long-term prognosis of ulcerative colitis and its temporal changes between 1986 and 2015 in a population-based cohort in the Songpa-Kangdong district of Seoul, Korea. Gut 2020;69:1432-1440.

14. Aniwan S, Limsrivilai J, Pongprasobchai S, et al. Temporal trend in the natural history of ulcerative colitis in a country with a low incidence of ulcerative colitis from 2000 through 2018. Intest Res 2021;19:186-193.

15. Gupta RB, Harpaz N, Itzkowitz S, et al. Histologic inflammation is a risk factor for progression to colorectal neoplasia in ulcerative colitis: a cohort study. Gastroenterology 2007;133:1099-1105.

16. Lee CK, Lee KM, Park DI, et al. A new opportunity for innovative inflammatory bowel disease research: the Moderateto-Severe Ulcerative Colitis in Korea (MOSAIK) cohort study. Intest Res 2019;17:1-5. 